\title{
A late injection combustion strategy using a novel ramped combustion system
}

\author{
Author, co-author (Do NOT enter this information. It will be pulled from participant tab in \\ MyTechZone) \\ Affiliation (Do NOT enter this information. It will be pulled from participant tab in MyTechZone)
}

\begin{abstract}
Traffic related NOx and particle emission remain a significant concern particularly in the urban environment. Electrification offers a medium to long term solution, but there remains a need to significantly reduce internal combustion engine emissions in the short and medium term, and potentially in the long term for long range inter city transportation. Late injection low temperature combustion (LTC) has the potential to achieve ultra-low emissions levels in a compression ignition engine by increasing the lean pre-mixed burn fraction. However, significant quantities of diluent are normally required to achieve the required delay in ignition and pre-mixing to achieve LTC. This results in high boost requirements, increased pumping work and the complexity of the air handling system and potentially adversely impacting fuel economy. In this paper, results from a single cylinder light duty research engine are presented using a novel ramped combustion chamber focused at mid to high engine loads. The ramped combustion chamber improves mixing and enables more retarded injection timings than those possible on conventional bowl designs. This combustion strategy has enabled LTC conditions to be achieved at lower dilution rates, typically 20$30 \%$ at loads up to 15bar IMEP. CFD analysis of the air-fuel interaction indicates the ramped bowl effectively deflects fuel away from the squish region enabling very late injection timings. One dimensional analysis of the engine system was used to investigate the potential of late exhaust valve opening in improving work recovery, resulting in improved fuel consumption over the baseline LTC valve timings.
\end{abstract}

\section{Introduction}

Diesel exhaust emissions remain a major concern in the urban environment [1]. The introduction of the new WLTC [2] cycle and Realistic Driving Emissions (RDE) standards [3] has significantly extended the areas of the engine operating map where the vehicle must be calibrated to achieve ultra-low tailpipe emissions. A homogenous charge compression ignition (HCCI) combustion system has the potential to achieve simultaneously near zero noxious tailpipe emissions and high thermal efficiency [4]. However, control of the combustion process between the knock and misfire limits has remained challenging. This control challenge has limited the load and speed range with HCCI and therefore ultra-low emissions can be achieved, particularly at higher engine loads experienced under WLTC test conditions. The use of two fuels of different reactivity, commonly referred to Reactivity Controlled Compression Ignition (RCCI) [5] provides additional control of the main ignition event through the injection of the second high reactivity fuel. However, the concept requires two fuel systems and two fuels to be carried on the vehicle increasing complexity and therefore cost. Some of the benefits of HCCI and RCCI combustion strategies can be achieved by increasing Page 1 of 8 the pre-mixed fraction of a conventional diesel combustion system, commonly referred to as Low Temperature Combustion (LTC) [6] or sometimes Diesel Low Temperature Combustion. This is achieved by the introduction of significant quantities of diluent, typically via Exhaust Gas Recirculation (EGR) and injecting the fuel either early or late to increase the ignition delay, also giving the fuel and air more time to mix before ignition. A proportion of the fuel will still burn in a stratified condition, as in a conventional diesel combustion system, so all the potential benefits realized by a HCCI or RCCI combustion strategy will not be achieved. However, the strategy presents an interesting compromise between a full $\mathrm{HCCI}$ engine and conventional stratified Diesel compression ignition engine. Both the early and late LTC strategies were comprehensively described by Musculus through direct observation of the in cylinder processes using laser diagnostics [7]. The high hydrocarbon emissions often observed with late injection LTC were attributed to (a) over leaning of the mixture in the central region of the combustion chamber (b) fuel washing over the top of the piston crown forming a film on the metal surfaces and (c) incomplete combustion of poorly atomized fuel released from the sac volume after the main injection event. It was also reported the UHC emissions from mechanism (c) reduced at higher engine loads.

In this paper, the potential of a novel ramped combustion chamber operating a late injection Diesel LTC strategy will be assessed. The study was focused at mid to high load conditions at 2000rpm, beyond the range normally considered for traditional drive cycle emissions such as the NEDC. Higher load conditions were selected to assess the combustion system as a means of extending practical LTC operation for a downsized diesel engines compliant with WLTC and RDE emissions control standards. The ramped combustion system and why the chamber geometry is potentially suitable for LTC is first described. A brief description of the test facility and experimental approach is then presented followed by results focused initially at a mid-load key point of 9bar IMEP at 2000rpm and then higher loads up to $15 \mathrm{bar}$ IMEP. Computational Fluid Dynamics (CFD) analysis of a baseline re-entrant and the new ramped combustion bowls are then presented to further investigate the fuel - air interaction and provide more supporting evidence for the hypothesis. The paper concludes with results from cycle analysis of the potential of using Miller valve timings to improve the fuel consumption of the combustion system.

\section{Late Injection Low Temperature Combustion}

The LTC combustion mechanism was comprehensively described by Musculus [7]. Musculus proposed a conceptual model for LTC and compared the mixing, ignition and combustion processes with the Sandia conceptual model for conventional compression ignition combustion [8]. Differences between small bore light duty and larger bore heavy duty engines were observed; for this research, we are 
concentrating on a light duty small bore engine. Several features of the LTC process were reported as follows:

- A $1-2^{\circ}$ of additional ignition delay over a conventional diesel combustion system was observed in LTC conditions

- Strong interaction of the piston with the liquid fuel jet

- More prominent role of reverse squish

- Regions of incomplete combustion and late film vaporization leading to $\mathrm{CO}$ and unburnt hydrocarbon (UHC) emissions

High dilution levels - typically provided by EGR are required to deliver the required delay in ignition and control the rate of combustion of the pre-mixed fraction, which could otherwise burn very quickly resulting in unacceptable noise through 'ringing' [6]. The high UHC emissions - often reported for LTC - were shown to be in part caused by fuel washing over the top of the piston, forming a film on the piston and cylinder head surfaces and potentially becoming trapped in the crevice areas. (Figure 1a).
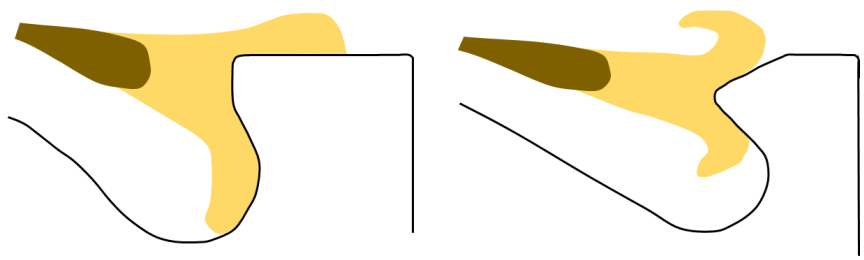

Figure 1 (a) Conceptual model of late injection LTC adapted from [7] and (b) fuel piston interaction for the ramped combustion chamber.

In the research presented in this paper, a ramped combustion chamber (referred to as bowl B6) was used. The bowl was developed for conventional injection timings as a means of delivering low particulate emission at high EGR rates at high load $[9,10]$. The bowl differs from other ramped chambers such as [11], in that the chamber shape is designed to promote improved mixing by splitting the impinging fuel spray and directing the jet back into the combustion bowl (figure $1 \mathrm{~b}$ ). Considering the conceptual model described above, the ramped combustion chamber could also be effective at preventing fuel vapor washing over the combustion bowl lip onto the top of the piston crown, resulting in quenching and poor quality combustion.

\section{Test facility}

A Ricardo hydra engine, installed in the Sir Harry Ricardo Laboratory at the University of Brighton was used for the work. The engine was a single cylinder diesel engine fitted with a Delphi common rail fuel system. Key engine parameters are summarized in table 1 and a picture of the installed engine in figure 2. The air into the engine was supplied via a set of nozzles operated in choked conditions. This setup enabled the pressure pulsations induced by the engine intake event and air supply system to be isolated, stabilizing the air flow to the engine and providing a means of accurately measuring the air mass flow. EGR was supplied via the short route between a back-pressure valve in the exhaust and upstream of the inlet manifold, to ensure good mixing of the EGR and charge air. The EGR was cooled and the air pre-heated to enable the inlet manifold temperature to be accurately controlled. The engine was comprehensively instrumented to measure key temperatures and pressures around the system. High speed pressure transducers were fitted to measure the cylinder, inlet port, exhaust port and fuel pressure as well as the injector drive current. Gaseous emissions were measured using a Horiba Mexa 7000, particulate with an AVL415s smoke meter and fuel flow using an AVL733s fuel meter.
Specific particulate emissions were calculated from the smoke measurements using the AVL method. Reference diesel fuel RF06-08B5 was used for the duration of the test programme.

The Delphi DFR 1.5 common rail fuel system was used for the work. The injector was controlled using a custom-made ECU. Injection timing was measured using a current clamp fitted to the injector control wires and measured on a high-speed logger. Injection timings quoted in the paper are from the start of current rise measured from the highspeed logger and therefore, the actual start of injection will be later due to electronic and hydraulic delay.

\begin{tabular}{|l|l|}
\hline Fuel system & $\begin{array}{l}\text { Delphi DFR1.5 with 2000 bar injection } \\
\text { pressure capability }\end{array}$ \\
\hline Injector & $\begin{array}{l}8 \text { hole, 0.123mm hole diameter, 155 } \\
\text { cone angle }\end{array}$ \\
\hline Engine & $\begin{array}{l}\text { Ricardo 498cc hydra with 200bar peak } \\
\text { firing pressure }\end{array}$ \\
\hline Bore & $84 \mathrm{~mm}$ \\
\hline Stroke & $90 \mathrm{~mm}$ \\
\hline Compression Ratio & $16.3: 1$ \\
\hline Swirl Ratio & 1.75 \\
\hline
\end{tabular}

Table 1: Engine parameters

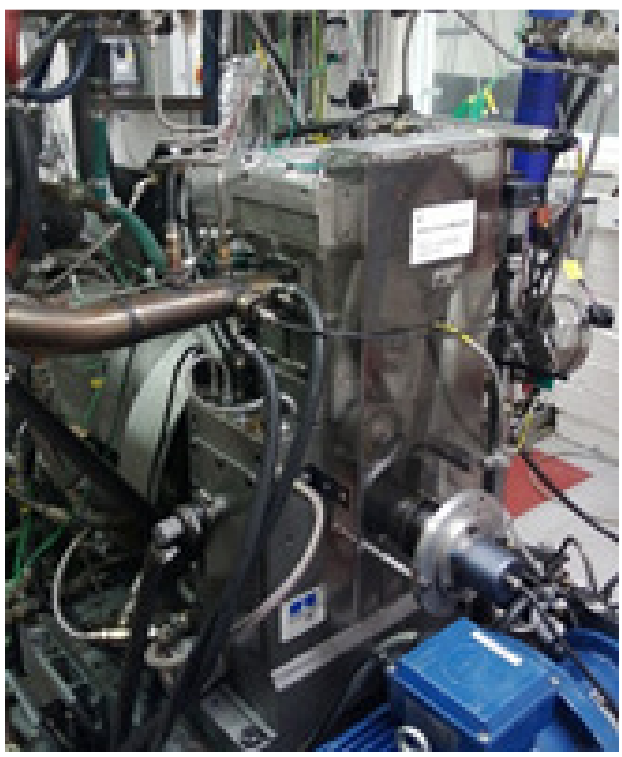

Figure 2: Hydra Engine Installed at the University of Brighton

Two combustion chamber geometries were used for the research; a conventional re-entrant combustion chamber (B2) and a novel ramped combustion chamber (B6). The two combustion chambers are shown schematically in figure 3 . 


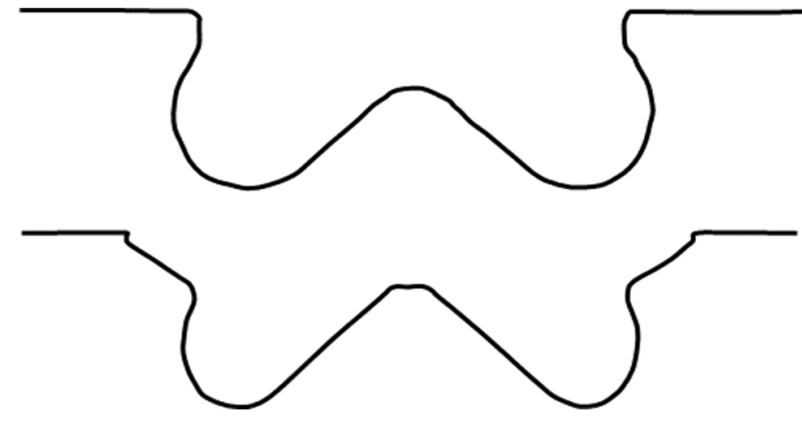

Figure 3: Schematic of the baseline, B2 (top) and ramped, B6 (bottom) pistons.

\section{Test Program and Results}

\section{9 bar IMEP key Point}

The first block of testing was focused at a 9bar IMEP 2000rpm key point. This point was selected as a condition that LTC had been achieved by others (based on a review of the literature) but at a load higher than what would normally require emissions control under historic test cycles such as the NEDC. As previously mentioned, the new WLTC cycle and future RDE regulations will require emissions control at much higher loads than were historically required, therefore, it was decided this was a reasonable key point to study first.

The nozzle geometry, protrusion and swirl ratio were fixed, based on a multi key point study [12] using a conventional Diesel combustion strategy (without use of LTC), targeting Euro 6 emissions levels. These parameters were not re-optimized for late injection, it was assumed LTC would not be the optimal strategy across the whole load (speed range of the engine). Therefore, to avoid compromising performance at other key points, the previously defined injector configuration was retained. It should be noted that the injector protrusion and spray angle would result in the spray now being targeted 0.5-1.0 mm higher than the optimal due to the position of the piston further down the stroke at the late injection timings at the start of injection. The spray could be re-targeted by changing either the protrusion or cone angle, but this was not done, as it was assumed the LTC strategy would not be used at all key points. Thus, changing the spray target would compromise other key points and so the previous set up was retained.

Results comparing an injection timing swing using bowl B2 and B6 are shown in figure 4. A drop in specific particulate emissions at very late timings was observed for B6 - opposite to the normal trend of increased particulate emissions, with later injection timings observed in B2. Lower particulate emissions were achieved at earlier higher NOx conditions for B2 but overall lower emissions were achieved for B6 at later timings. It should be noted that from previous work on these combustion chambers reported in [12] using conventional injection timings, neither bowl was clearly superior at all key points with the ramped chamber superior at higher speed and load conditions. At the selected condition for this work, B2 is superior at conventional injection timings but the LTC strategy provides an option of achieving ultra-low emissions and potentially the overall cycle trade off. Further work is required to assess the impact of this strategy on full cycle trade off.

Results comparing an injection timing swing using bowl B6 and work on a similar engine from reference [13] are shown in figure 5. It can be seen that much lower NOx and particulate emissions were achieved at

Page 3 of 8
35\% EGR and at very low NOx levels, there was a significant particulate emissions penalty at the higher EGR rates required for the conventional combustion system. At higher EGR (40-50\%) rates, slightly lower NOx emissions could be achieved using the conventional chamber rather than 35\% EGR data from B6 but at a significant particulate emissions penalty.

In summary, B6 has the interesting characteristic of achieving very low NOx and Pm emissions at late injection timings at modest EGR rates. The characteristic dip in particulate emissions at very late injection timings was observed even at EGR rates as low as $15 \%$. With the current focus on urban air quality, this strategy could be a useful tool in achieving low cycle emissions through the control of in-cylinder emissions formation reducing the need for post combustion after treatment.

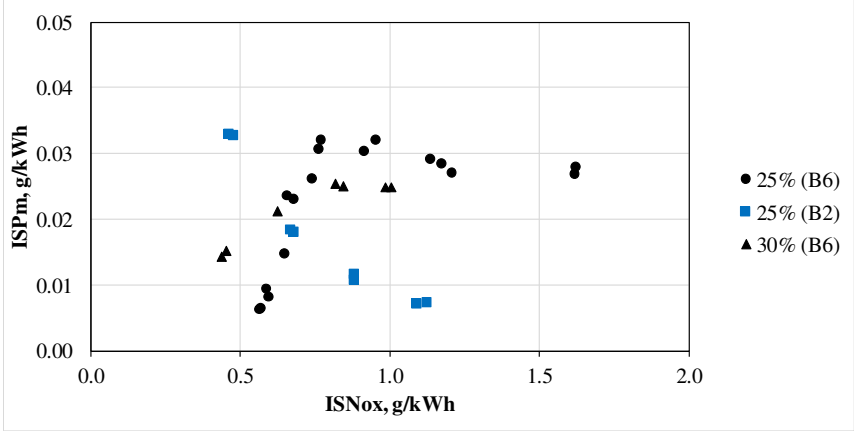

Figure 4 Timing swings at 9bar IMEP 2000rpm for bowl B2 and B6 at varying EGR rates. Other test conditions set to $1200 \mathrm{bar}$ rail pressure, $42^{\circ} \mathrm{C}$ inlet temperature and 20:1 AFR. Injection timings were varied from $-14^{\circ}$ to $-2^{\circ}$ ATDC for $B 6$.

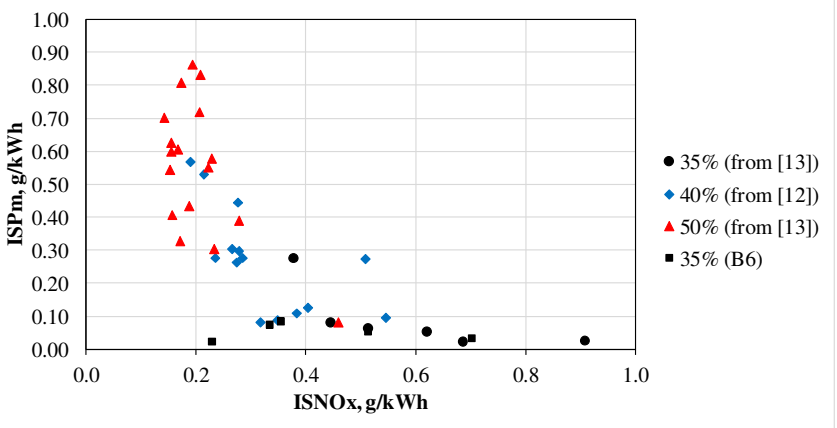

Figure 5 Timing swings at 9bar IMEP 2000rpm for bowl B6 and a conventional chamber from [13] at varying EGR rates. Other test conditions set to $1200 \mathrm{bar}$ rail pressure, $42^{\circ} \mathrm{C}$ inlet temperature and 20:1 AFR.

A single factor optimization study was then undertaken considering air fuel ratio, rail pressure and injection timing. An AFR of 20:1 was found to achieve LTC conditions. At lower AFR, the fuel consumption degraded significantly, whereas conversely little benefit was observed at higher AFR's. The AFR was then fixed at 20:1 for further investigation at the 9bar 2000rpm test condition.

A series of EGR timing swings were then undertaken to investigate the effect of dilution on performance and emissions. Plots showing the variation of various parameters with NOx emissions are shown in figure 6 . The reversal of the NOx particulate curve at retarded timings was observed at EGR rates as low as $15 \%$. At above $30 \%$, an initial 
increase in particulate emissions was observed at retarded injection timings before a drop for very late timings, indicating increased premixed combustion. At $20-25 \%$ EGR the particulate emissions were largely unchanged as the timing was retarded before the drop in particulate emissions at very late timings. In all cases at the late injection timings, the $\mathrm{CO}$ and $\mathrm{UHC}$ emissions were observed to increase showing the reverse trend to the particulate emissions. The combustion was therefore incomplete at the late injection timings, consistent with the findings of Musculus [7].
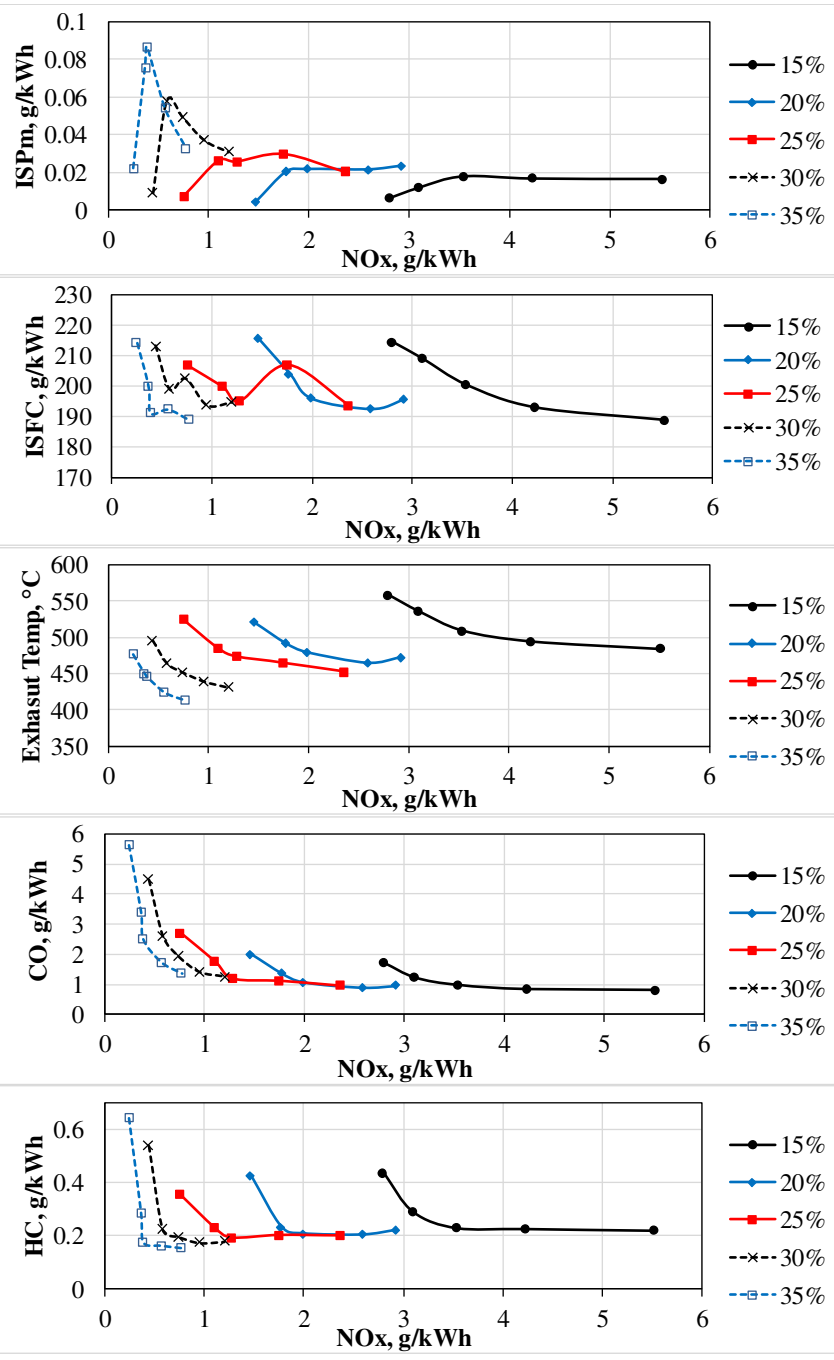

Figure 6 Results from timing swings for bowl B6 at 9bar IMEP $2000 \mathrm{rpm}$ at different EGR rates. Other test conditions; $42^{\circ} \mathrm{C}$ inlet, 20:1 AFR, 1200bar rail. Injection timings were varied in the range of $-14^{\circ}$ to $-2^{\circ}$ ATDC.

\section{9-18 bar IMEP key Point}

A series of load points were tested from 9 to 18 bar IMEP using the B6 bowl. The rail pressure was increased from 1400 to 1600 bar and the AFR from 20 to 22:1 for the 15bar to 18bar IMEP conditions which was found to improve the fuel consumption trade off. The EGR rate was maintained at $25 \%$ and the inlet manifold temperature $42^{\circ} \mathrm{C}$. Injection timings were varied from -14 to $-2^{\circ}$ ATDC except for the $18 \mathrm{bar}$ condition where the limit of timing retard was $-3^{\circ}$ ATDC.
The NOx particulate curves for the four load conditions are shown in figure 7. The drop in particulate emissions for late injection timings was observed up to 15bar IMEP, indicating the conditions for LTC could be achieved at modest EGR rates using the ramped combustion system up to this load point. However, at 18bar IMEP the injection timing could not be sufficiently retarded to achieve the LTC conditions before the engine suffered unstable combustion and misfire. At the limit of injection timing retard achieved, the drop in particulate emissions observed at the lower load conditions was not observed, indicating the transition to a high partially pre-mixed combustion was not achieved. From this we conclude LTC could not be achieved using the late injection, (modest EGR strategy utilized at the 9-15bar IMEP conditions).

From this limited study, it is apparent LTC can still be achieved at up to 15 bar IMEP which would mean the strategy can be used for much of the engine operating map and certainly extended well beyond the NEDC controlled area of the map. This is particularly important with the move to the WLTC cycle and introduction of RDE regulations. Further work is required to investigate and optimize the strategy but early results are encouraging.

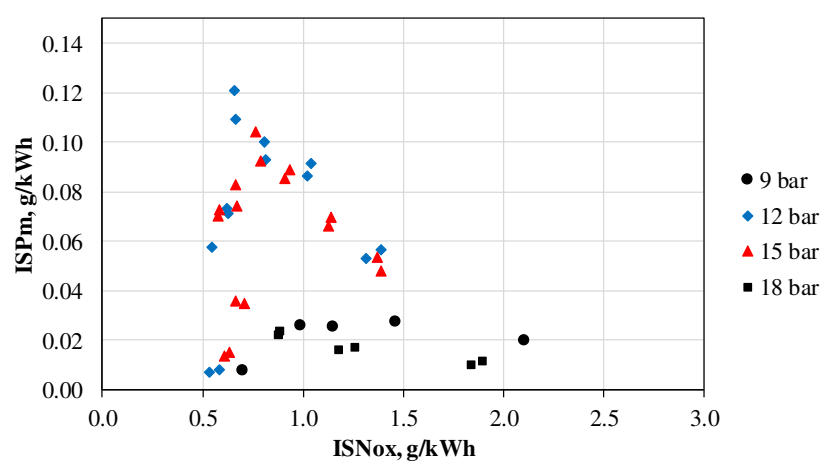

Figure 7. Results from timing swings at $2000 \mathrm{rpm}$ at different loads for a fixed EGR rate of $25 \%$ and inlet temperature of $42^{\circ} \mathrm{C}$.

\section{Combustion Analysis Test Results}

The cylinder pressure data gathered during the program was analyzed to calculate the rate of heat release and derive a range of diagnostic parameters such as start of combustion, maximum rate of pressure rise, $50 \%$ burn angle and combustion period. The data was processed using the normal method described in [12], with the cylinder pressure pegged to the inlet pressure measured during valve opening.

Figure 8 shows the relationship between the electronic start of injection timing to the $5 \%$ burn angle for a range of EGR conditions. Assuming the electronic and hydraulic delay contribution to the overall delay remains constant with injection retard, any change in the total delay can be attributed to changes in the in-cylinder ignition characteristics. It can be seen at the late injection timings where LTC was observed, the ignition delay is increased by $2-4^{\circ}$ relative to the more advance injection timings. This observation is consistent with those reported by Musculus [7].

The longest ignition delay increase was seen for the 25\% EGR conditions and not the higher EGR condition of 30-35\%. It would be expected that increased dilution would result in the longest ignition delay. The experiment was conducted at a constant AFR of 20:1. 


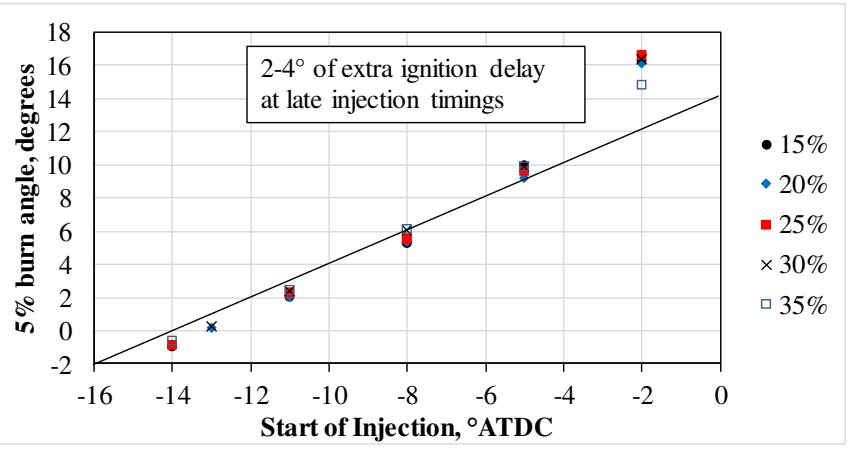

Figure 8 Influence of EGR on the ignition delay under LTC conditions at 9bar IMEP 2000rpm. Other test conditions; $42^{\circ} \mathrm{C}$ inlet, 20:1 AFR, 1200 bar rail pressure.

The introduction of EGR will therefore increase the trapped mass in the cylinder at the start of compression and therefore increase the motored cylinder pressure at TDC and during fuel injection and mixing. There is a well know inverse relationship between ignition delay and cylinder pressure, such as the empirical relationship proposed by Watson [14]. Therefore, in a practical engine the dilation effect of the EGR and increased chamber pressure work in opposition and explain at least part of the observed result.

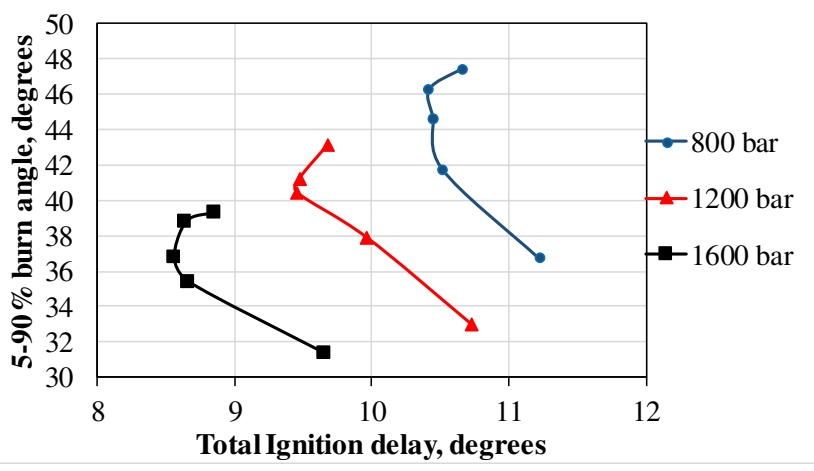

Figure 9 Relationship between $\mathbf{5 - 9 0 \%}$ burn angle and ignition delay for three rail pressures at 9bar IMEP 2000rpm. Other test conditions; $42^{\circ} \mathrm{C}$ inlet, 20:1 AFR and $25 \%$ EGR.

Further analysis of the 5-90\% burn period was undertaken to study the relationship between the ignition delay and the combustion period (figure 9). The 5-90\% burn angle was derived from the cylinder pressure data and the ignition delay is again defined from the sending of the electronic pulse to the injector to the $5 \%$ burn angle. As the injection timing is varied, the chamber pressure profile during the injection, mixing and ignition events will also vary, with the initial injection and mixing event occoring at higher pressure for the more advanced injection timings. Refering to figure 9 , as the ignition delay is lengthened the $5-90 \%$ burn period shortens indicating more rapid initial burning of the fuel. This is consistent with a larger fraction of the fuel reacting in a pre-mixed state. As expected with increased rail pressure, the ignition delay was observed to decrease. The corresponding burn angle also increases, as the injection event is longer and so the final fraction of fuel is introduced into the combustion chamber later for lower rail pressures. The longer ignition delay at lower rail pressures would favour pre-mixing, but the longer injection period is overall detrimental as more fuel is injected late in the expansion stroke potential, increasing $\mathrm{CO}$ and UHC's.

Page 5 of 8

\section{Mixing and Combustion Analysis}

\section{Model Calibration}

To investigate further the in-cylinder processes, computational fluid dynamics (CFD) was used to model the air-fuel mixing and combustion processes inside the engine for both the conventional B2 and ramped B6 bowels. The Ricardo VECTIS package was used for the analysis; first, the model was calibrated to the motoring curve and then the spray model tuned for one combustion condition. The settings were then held constant and the simulation ran for a range of injection timings. The cylinder pressure and NOx response with injection timing was picked up reasonably well by even this simple CFD model (figure 10 ), giving confidence that the simulation was correctly picking up most of the complex thermos-fluid processes in the combustion chamber.

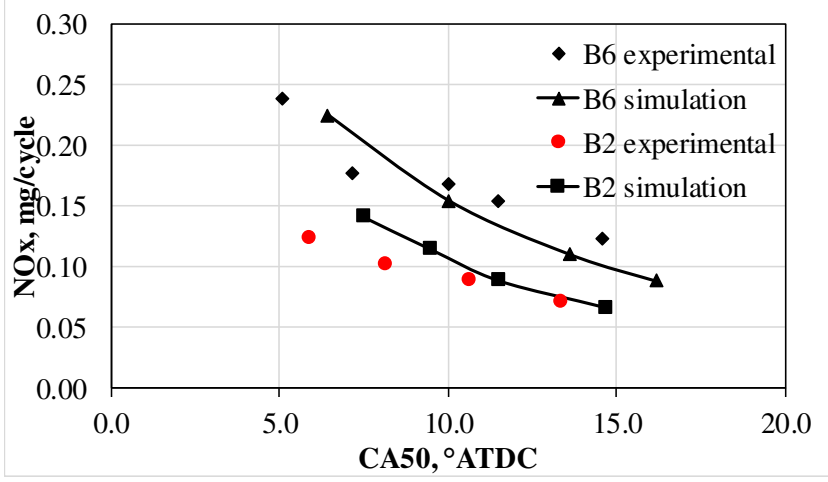

Figure 10 Measured and predicted $\mathrm{NO}_{\mathrm{x}}$ for bowls $\mathrm{B} 2$ and $\mathrm{B} 6$ against CA50 angle. Test condition 2000rpm 9bar IMEP at 25\% EGR, 20:1AFR, 1200bar rail pressure and $42^{\circ} \mathrm{C}$ inlet temperature.

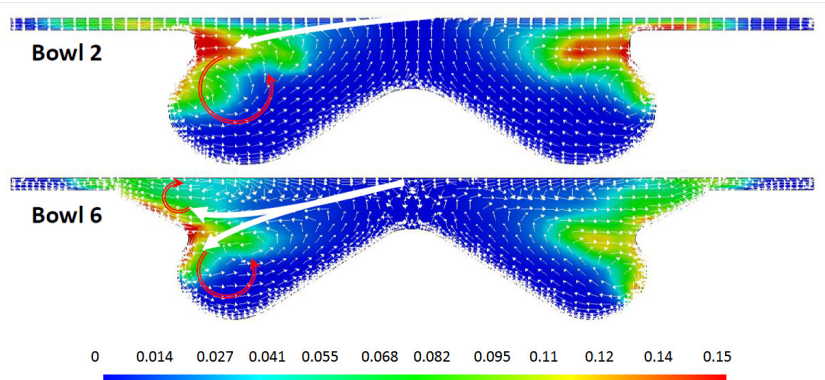

Figure 11 Air motion (arrows) and fuel mass fraction (color scale) for bowls B2 and B6 at SOI $-9^{\circ}$ ATDC.

The effect of the ramped combustion chamber on the predicted motion of the air and fuel can be seen in figure 11 for a conventional advanced injection timings of $-9^{\circ}$ ATDC. The splitting of the fuel spray by the bowl lip feature and pulling of the fuel spray away from the squish region can be clearly seen in the simulation, generating two vortex motions visible in the vertical cut plain. The improved mixing of the ramped combustion bowl can be seen in smaller regions of rich fuel and improved distribution of the fuel within the bowl. 


\section{Comparison of Bowl B2 and B6 Mixing}

The primary motivation for the CFD study was to assess the air-fuel mixing at late injection timings and to provide supporting evidence to the conceptual interpretation of the experimental data. A series of plots showing the predicted equivalence ratio for a series of crank angles, for both the B2 and B6 bowls with advanced and retarded injection timings, are shown in figure 12 . The condition simulated was the 2000rpm 9bar IMEP point with the inlet conditions set to 25\% EGR, 20:1 AFR and $42^{\circ} \mathrm{C}$ inlet temperature.

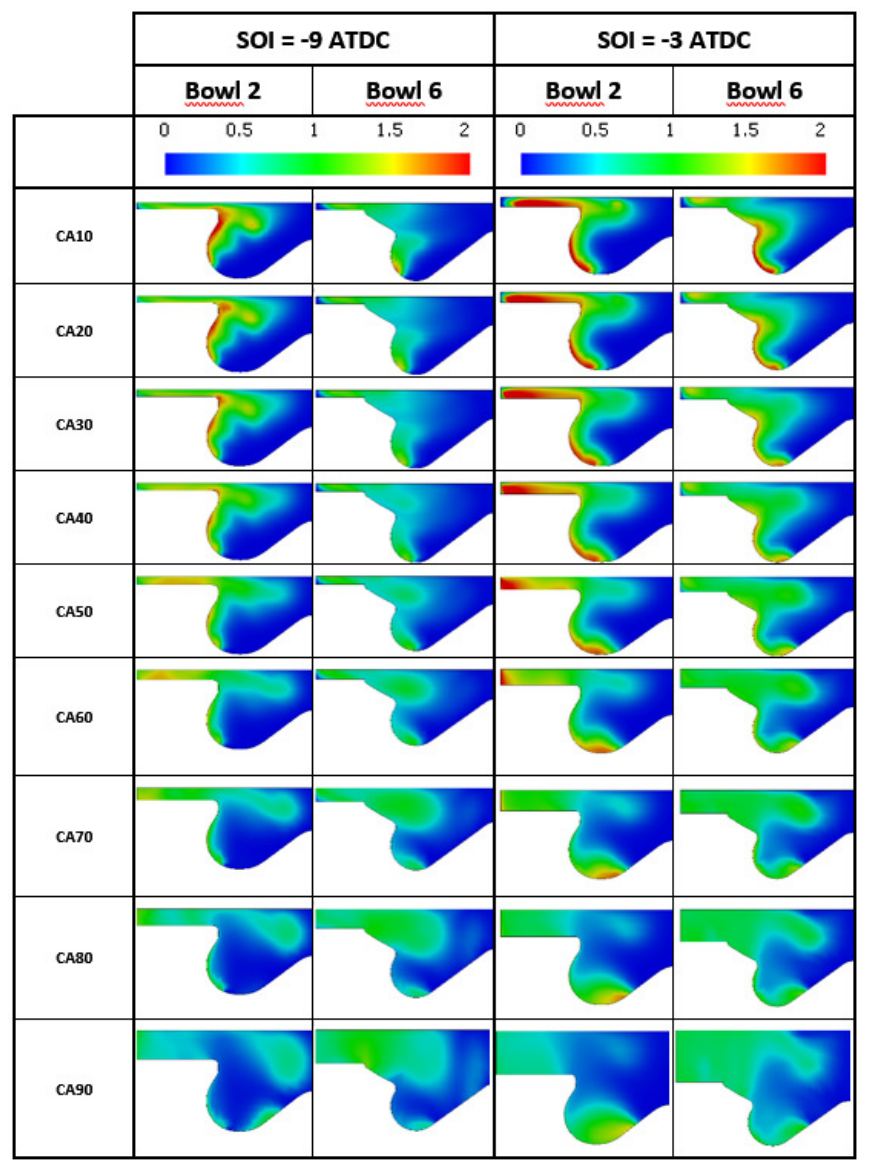

Figure 12. Comparison equivalence ratio across the combustion chamber for bowls B2 and B6 at LTC injection at 2000rpm 9bar IMEP point with the inlet conditions set to $25 \%$ EGR, 20:1 AFR and $42^{\circ} \mathrm{C}$ inlet temperature.

Comparing the two bowls, as the simulation progresses, it is evident more of the fuel is retained in the combustion chamber for B6, evidenced by fuel rich regions predicted by the simulation in the squish area for B2 at the retarded timing. Focusing on the 50\% burn angle results, the fuel - air equivalence ratio for B2 is 1.5 in the squish region, which would be too rich for complete combustion and would result in UHC and $\mathrm{CO}$ emissions. By comparison, equivalence ratio for B6 is 0.9 and so more complete combustion would be expected for this geometry. Very rich regions are also evident early in the mixing and combustion process along the top of the piston for the late injection timings for B2, whereas the fuel is largely deflected into the combustion chamber for B6. Liquid fuel would be expected to form a film on top of the piston and could become trapped in the crevice regions of the piston on $\mathrm{B} 2$, whereas $\mathrm{B} 6$ does not show rich mixtures in these areas. It is interesting to note the early injection timings do show B2 contains the fuel effectively in the bowl, in line with the test results that indicate the combustion chamber is working correctly. The general mixing for bowls B2 and B6 for the early injection timings Page 6 of 8 does not look significantly different, again, in line with the test results reported in [12].

The CFD analysis therefore effectively discriminates between the observed behaviors from the test program and supports the observation that B6 is considerably more tolerant to late injection timings. The original hypothesis proposed that the ramped bowl deflects fuel through a twin vortex motion is also supported by the analysis results.

\section{One dimensional simulation of Miller valve timings}

An inevitable consequence of the late injection timings is that combustion products will be under-expanded unless the valve timings are re-optimized. There is benefit in maintaining the baseline compression ratio to enable the engine to operate with conventional injection timings at some points, especially rated load conditions. A variable compression ratio strategy could be considered but will increase mechanical complexity of the powertrain. Instead, the potential of adopting a Miller valve strategy was investigated. The selected strategy was to vary the exhaust valve period with a fixed valve closure position. The effective expansion stroke could then be varied without changing the compression stroke.

The scavenging of the combustion chamber would be affected but these effects were captured in the simulation. The Ricardo WAVE 1D gas exchange code was used for the analysis. A model of the single cylinder engine was built and matched to the experimental data. The motoring curve was first matched across a range of speeds and the air mass flow checked against the experimental results. The combustion model was then tuned to match the measured cylinder pressure by adjusting the double Wiebe function was used to simulate the heat release. After matching the motoring pressure and tuning the combustion model, these parameters were held constant.

The 9bar IMEP 2000rpm key point described above for the CFD analysis was selected for the study. The exhaust valve opening time was swung from $30^{\circ}$ early to $50^{\circ}$ later than the baseline of $135^{\circ}$ ATDC. Regarding figure 13, the exhaust valve period was increased and decreased relative the baseline timings for an early injection strategy (SOC phased to TDC) and LTC strategy, with the SOI set to $-2^{\circ}$ ATDC. The baseline valve timings are very close to the optimal for this key point with little benefit observed in delaying ECO. However, in the case of the LTC, delaying valve closure by $20^{\circ}$ crank reduced the fuel consumption penalty from $11 \%$ to $6 \%$. The flexibility offered by Miller type of valve timing therefore recovers some of the fuel consumption penalty observed through the adoption of the late injection LTC strategy. The adoption of a miller timing strategy would come at the cost of additional complexity to the valve train and so, must be assessed across the whole operating range. The later valve opening will also reduce exhaust energy, but with reference to figure 6 , the exhaust temperature does increase at the late injection timings and so the later valve opening recovers excess exhaust energy that would otherwise be lost. Another benefit of the proposed strategy is the pumping losses incurred through the introduction of EGR would be lower than other strategies using higher EGR rates, reducing the turbocharger work requirements. 


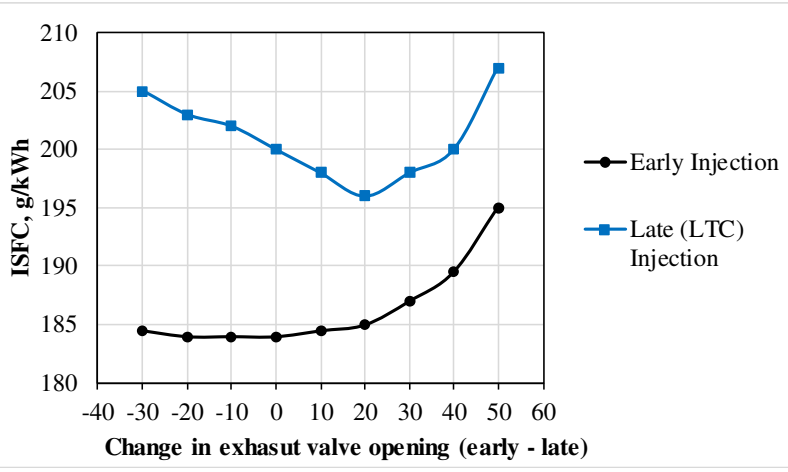

Figure 13. Predicted fuel consumption with Miller valve timings for conventional and late injection timings 9bar IMEP 2000RPM

\section{Discussion}

The motivation for the study was to investigate the potential of a ramped combustion system in achieving ultra-low emissions, in particular at the high loads that are now much more important with the changes to the emissions test cycles for light duty vehicles. The ramped combustion chamber is certainly much more tolerant to late injection timings and so lower engine out $\mathrm{NO}_{\mathrm{x}}$ emissions can be achieved using a late injection strategy. The interesting feature of the ramped combustion chamber is very low particulate emissions can also be achieved at late injection timings, indicative of LTC conditions. The late injection strategy is therefore able to simultaneously reduce NOx and particulate emissions, but at a penalty in higher UHC's and CO emissions. However, these emissions are readily controlled by an oxidation catalyst commonly fitted to light duty diesel vehicles. LTC conditions are also achieved at a fuel consumption penalty which can be reduced to $6 \%$ relative to the best fuel consumption point by the adoption of a late exhaust valve opening strategy, improving expansion work recovery with late combustion.

At this stage of the research, the potential overall benefit of the combustion strategy across the vehicle drive cycle has not been assessed. LTC combustion was not achieved at the highest load points likely to be required for a light duty diesel vehicle and so a blend of strategies will be required. It is important to note the LTC conditions were achieved using the hardware configuration previously optimized for a conventional low emissions diesel combustion system. This was in terms of bowl shape, swirl, injector nozzle geometry and protrusion. The combustion system performed well in this configuration in both conventional and LTC modes of operation. This has the potential to give useful flexibility when calibrating the vehicle for the demanding WLTC - RDE regulations, where emissions must be controlled over more of the engine operating map. The option of lowering engine out emissions at some operating points could reduce the size and complexity of the after treatment system on the vehicle, reducing the cost of the powertrain package. The whole system trade off will be the subject of future research.

\section{Conclusions}

A late injection low temperature combustion (LTC) strategy was successfully implemented on a light duty diesel engine with a ramped piston bowl. The following conclusions were made on the performance of the ramped bowl, relative to a conventional re-entrant chamber:
- The improved air fuel mixing generated by the ramped bowl enables stable combustion, at acceptable hydrocarbon emissions at later injection timings, than those possible on a conventional reentrant combustion chamber

- The ramped combustion chamber achieved late injection LTC conditions, defined by a drop in particulate emissions to near zero at late injection timings and an increase in the ignition delay by $2^{\circ}$ $4^{\circ}$.

- The LTC condition was achieved at roughly half the EGR rates required on previous studies due to the tolerance of the combustion system to late injection timings

- LTC was demonstrated at up to 15bar IMEP. At higher loads, the combustion became unstable before LTC conditions were achieved

- CFD analysis provides understanding as to why the bowl is performing well at late injection timings and provides a tool for further research and development

- CFD analysis of the air-fuel mixing process showed the ramped chamber is effective in keeping the fuel in the combustion chamber and away from the squish region, consistent with the Sandia model for LTC

- Ultra-low particulate emissions at $<0.5 \mathrm{~g} / \mathrm{kWh} \mathrm{NOx}$ can be achieved at 9 bar IMEP with a $11 \%$ fuel consumption penalty

- 1D Analysis indicates that the adoption of Miller valve timings will recover some of the fuel consumption penalty, reducing the penalty to $6 \%$

\section{References}

1. Miranda, A.I., et al., A cost-efficiency and health benefit approach to improve urban air quality. Science of The Total Environment, 2016. 569-570: p. 342-351.

2. Tutuianu, M., et al., Development of the World-wide harmonized Light duty Test Cycle (WLTC) and a possible pathway for its introduction in the European legislation. Transportation Research Part D: Transport and Environment, 2015. 40: p. 61-75.

3. Available from: http://europa.eu/rapid/press-release_IP-155945_en.htm. Accesed 5/6/2017

4. Agarwal, A.K., A.P. Singh, and R.K. Maurya, Evolution, challenges and path forward for low temperature combustion engines. Progress in Energy and Combustion Science, 2017. 61: p. 1-56.

5. Reitz, R.D. and G. Duraisamy, Review of high efficiency and clean reactivity controlled compression ignition (RCCI) combustion in internal combustion engines. Progress in Energy and Combustion Science, 2015. 46: p. 12-71.

6. Saxena, S. and I.D. Bedoya, Fundamental phenomena affecting low temperature combustion and HCCI engines, high load limits and strategies for extending these limits. Progress in Energy and Combustion Science, 2013. 39(5): p. 457-488.

7. Musculus, M.P.B., P.C. Miles, and L.M. Pickett, Conceptual models for partially premixed low-temperature diesel combustion. Progress in Energy and Combustion Science, 2013. 39(2-3): p. 246-283.

8. Dec, J.E., A Conceptual Model of DI Diesel Combustion Based on Laser-Sheet Imaging. SAE Technical Paper 970873, 1997.

9. Arnone, L., et al., Performance Development of a New Tier 4 Final Engine Family below $56 \mathrm{~kW}$. SAE Technical Paper 2013-24-0125, 2013.

10. Natti, K., et al., Studies on the Impact of $300 \mathrm{MPa}$ Injection Pressure on Engine Performance, Gaseous and Particulate Emissions SAE Technical Paper 2013-01-0897, 2013. 
11. Styron, J., et al., Ford 2011 6.7L Power Stroke ${ }^{\circledR}$ Diesel Engine Combustion System Development. 2011, SAE Technical Paper SAE2011-01-0415, 2011.

12. Higginson, S., A parametric study of combustion system design for a light duty diesel engine. 2015, University of Brighton.

13. Laguitton, O., The effect of compression ratio on exhasut emissiosn from a PCCI Diesel engine. 2007. University of Brighton.

14. Watson, N., A.D. Pilley, and M. Marzouk, A Combustion Correlation for Diesel Engine Simulation. SAE Int. J. Commer. Veh., 1980.

\section{Contact Information}

Dr Robert Morgan

University of Brighton

Cockroft Building

Lewes Road

Brighton BN24GJ

United Kingdom

r.morgan2@brighton.ac.uk

\section{Acknowledgments}

The work reported in this paper was funded by the EPSRC grant award EM/M009424/1 Ultra Efficient Engines and Fuels. The authors would like to thank Delphi for the supply of the DFI 1.5 fuel system and subsequent support and Ricardo Software for providing academic WAVE and VECTIS licenses. We would also like to thank Ricardo for their permission to use the Hydra engine used for the research. Finally, we would like to thank Christian Rota, Clement Delpech and Guillaume Alnet for their hard work during their internships at the University of Brighton.

\section{Definitions and Abbreviations}

ATDC

BTDC

CFD
After Top Dead Center.

Before Top Dead Center

Computational Fluid Dynamics
Filter Smoke Number

HCCI

LTC

NEDC

RCCI

RDE

SOC

SOI

TDC

Homogenous Charge

Compression Ignition

Indicated Mean Effective Pressure

Low Temperature

Combustion. (sometimes referred to as Diesel LTC)

New European Drive Cycle

Reactivity Controlled Compression Ignition

Realistic Driving Emissions

Start of Combustion

Start Of Injection

Top Dead Center

UHC

Unburn Hydrocarbon

WLTC
World Light-duty Transient Cycle 